\title{
Морфология, оптические и адсорбционные свойства слоев оксидов меди, осажденных из растворов комплексных соединений
}

\author{
(С Л.Б. Матюшкин ${ }^{1}$, А.А. Решетникова ${ }^{1}$, А.О. Андронов ${ }^{1}$, П.К. Афроничева ${ }^{1}$, С.В. Мякин ${ }^{2}$, \\ Н.В. Пермяков ${ }^{1}$, В.А. Мошников ${ }^{1}$ \\ ${ }^{1}$ Санкт-Петербургский государственный электротехнический университет „ЛЭТИ“, \\ 197376 Санкт-Петербург, Россия \\ ${ }^{2}$ Санкт-Петербургский государственный технологический институт (технический университет), \\ 190013 Санкт-Петербург, Россия \\ E-mail: leva.matyushkin@gmail.com
}

(Получена 17 ноября 2016 г. Принята к печати 28 ноября 2016 г.)

Рассмотрена методика синтеза газочувствительных слоев оксидов меди, полученных путем послойного осаждения на стеклянные и полимерные подложки по реакции окисления молекул аммиачного комплекса меди перекисью водорода. Слои, синтезированные при различном количестве циклов наслаивания, исследованы методами атомно-силовой микроскопии и спектроскопии пропускания (300-1000 нм). Форма спектров указывает на смешанный характер оксида с преобладанием оксида меди $(\mathrm{I}) \mathrm{Cu}_{2} \mathrm{O}$ с соответствующей шириной запрещенной зоны 2.1 э. Слои обладают сплошной зернистой структурой. Определенная химическим индикаторным методом поверхностная концентрация бренстедовских кислотных центров адсорбции с $p K_{a} \approx 2.5$ (ОН-групп кислотного характера) составляет для исходных пленок 560 мкмоль/м² и возрастает в три раза при термическом воздействии $80^{\circ} \mathrm{C}$ в течение 30 мин. Полученные результаты представляют интерес в использовании описанной технологии для создания активных слоев оксида меди в газочувствительных сенсорах, работающих при комнатной температуре.

DOI: $10.21883 /$ FTP.2017.05.44417.8452

\section{1. Введение}

Для создания датчиков контроля состава атмосферного воздуха большой интерес представляют такие материалы, как оксиды металлов, в частности оксиды меди $\left(\mathrm{CuO}\right.$ и $\mathrm{Cu}_{2} \mathrm{O}$ с шириной запрещенной зоны 1.2 эВ и 2.1 эВ соответственно) [1]. Преимуществами оксидов меди является их низкая стоимость и химическая стойкость. Пленки оксидов меди зарекомендовали себя в качестве чувствительного слоя газовых сенсоров для датчиков аммиака $\mathrm{NH}_{3}$ [2], оксида азота $\mathrm{NO}_{2}$ [3] и сероводорода $\mathrm{H}_{2} \mathrm{~S}$ [4]. Для последнего газа этот материал также используется в сочетании с оксидом олова [5].

Работа газочувствительных датчиков на оксидах металлов основана на изменении сопротивления образца под воздействием детектируемого газа, адсорбирующегося на поверхности полупроводника. Для существенного изменения сопротивления необходима развитая поверхность чувствительного слоя, т.е. высокая удельная площадь поверхности образца. Для процесса адсорбции детектируемых молекул важную роль играет состояние поверхности - количество и характер поверхностных адсорбционных центров. В случае газочувствительных металлоксидных слоев особенно важны бренстедовские кислотные центры с $p K_{a} \approx 2.5[6,7]$.

Среди различных методов получения тонких пленок важное место занимает метод ионного наслаивания (ИН), известный в зарубежной литературе как SILAR (Successive Ionic Layer Adsorption and Reaction) [8]. Методика заключается в последовательной адсорбции ионов на поверхности подложки, например, ионов ме- талла А и халькогена В для получения пленок полупроводниковых соединений $\mathrm{A}^{\mathrm{II}} \mathrm{B}^{\mathrm{VI}}$ и $\mathrm{A}^{\mathrm{IV}} \mathrm{B}^{\mathrm{VI}}$. В случае стандартной методики ИН, например для получения тонких пленок халькогенидов металлов (PbSe, CdTe, $\mathrm{ZnS}$ и т.д.), в качестве источников выступают два раствора: раствор соли, содержащей катионы необходимого металла $\left(\mathrm{A}^{2+}\right.$, например, для $\mathrm{Cd}^{2+}$ источником может служить $\left.\mathrm{CdCl}_{2}\right)$, и раствор соли, содержащей анионы халькогена $\left(\mathrm{B}^{2-}\right.$, например, для $\mathrm{S}^{2-}$ источником служит обычно $\left.\mathrm{Na}_{2} \mathrm{~S}\right)$. Функционализированная ОН-группами подложка последовательно погружается в растворы источников, расположенных в отдельных сосудах. При погружении подложки в раствор источника металла за счет предварительной функционализации поверхности подложки (например, ОН-группами) происходит преимущественная адсорбция катионов металла $\mathrm{A}^{2+}$, избыток которых удаляется в следующем сосуде с растворителем (обычно дистиллированной водой). Далее подложка с адсорбированными ионами $\mathrm{A}^{2+}$ перемещается в раствор с источником халькогена, ионы которого $\left(\mathrm{B}^{2-}\right)$ вступают в химическое взаимодействие с адсорбированным слоем, в результате чего на подложке образуется слой нерастворимого соединения АВ. Избыточные анионы $\mathrm{B}^{2-}$, физически адсорбированные на образце, но не участвующие в химическом взаимодействии, удаляются при последующем погружении в сосуд с растворителем. Так выглядит процедура, соответствующая одному циклу, выполняемая обычно при помощи автоматизированной электромеханической установки. Для получения пленок заданной толщины процедура повторяется необходимое число раз. 
Преимуществами такой методики являются возможность получения пленок при нормальных условиях (комнатной температуре и атмосферном давлении), на подложках различной природы (материал, морфология, размеры) с высокой точностью регулирования толщины синтезируемого слоя и сравнительной легкостью задания химического состава конечной пленки путем изменения состава растворов источников ионов. Отличительным преимуществом методики для развивающегося направления гибкой электроники является возможность получения тонких пленок при сравнительно низких температурах, что позволяет использовать в качестве подложек гибкую полимерную основу, в том числе изогнутой формы.

Однако в сравнении с традиционным методом ИН, рассмотренным в отношении халькогенидов металлов $\mathrm{MeX} \mathrm{[8],} \mathrm{в} \mathrm{случае} \mathrm{оксидных} \mathrm{соединений} \mathrm{общего} \mathrm{вида}$ $\mathrm{MeO}_{x}$ затруднительно применение данной методики. Это обусловлено присутствием кислорода в используемых растворителях и окружающей атмосфере, а также сложностью контролируемого использования какоголибо солевого источника кислорода. Поэтому интерес представляет применение комплексных соединений, разлагающихся до оксидов в результате изменения кислотности, теплового или химического воздействия и др. Для получения порошков металлооксидов используют также истинные растворы солей металлов, которые при взаимодействии с щелочами образуют гидроксид металла, который далее разлагается под действием нагрева:

$$
\mathrm{Me}(\mathrm{OH})_{2} \rightarrow \mathrm{MeO}+\mathrm{H}_{2} \mathrm{O}
$$

Однако необходимость высокотемпературного отжига нивелирует в данном случае такое преимущество метода, как низкие температуры синтеза. Кроме того, в работе [9] было установлено, что комплексные соединения, особенно аммиачный комплекс цинка, позволяют получать пленки $\mathrm{ZnO}$ более высокого качества, чем при использовании истинных растворов (например, $\mathrm{ZnCl}_{2}$ ). Процесс получения пленок может контролироваться такими факторами, как регулирование $\mathrm{pH}$ среды [10-12], температура реакции [13], дополнительное использование источников других ионов $[14,15]$, термический отжиг [11].

В данной работе предложена методика получения оксидов меди для газочувствительных структур, основанная на том, что в отличие от традиционного метода ионного наслаивания вместо диссоциирующего в растворе источника металла используется его комплексное соединение, а вместо источника халькогена - пероксид водорода. В силу принципиально другой природы осаждения слоев, в таком методе можно ожидать получения пленок оксида меди с развитой зернистой поверхностью. Важно отметить, что, поскольку в описанном методе в качестве источников ионов используются водные растворы солей, на поверхности образца создается большое количество гидроксильных центров адсорбции ОН-групп. Таким образом, предлагаемая методика интересна для создания газочувствительных структур.

\section{2. Методика эксперимента}

Для получения металлооксидных пленок применялась автоматизированная установка, описанная нами ранее для случая ионного наслаивания на примере получения сульфида кадмия [16,17].

В качестве подложек были выбраны предметное стекло и полиэстер. Размеры подложек составляли $1 \times 2 \mathrm{~cm}$ толщиной 1 мм для стекла и 0.1 мм для полиэстера. Предварительная очистка подложек проводилась в ультразвуковой ванне последовательно в ацетоне, изопропиловом спирте и дистиллированной воде. Для создания ОН-групп как стеклянные, так и полимерные подложки обрабатывались раствором концентрированной щелочи $(\mathrm{NaOH})$, после чего вновь промывались в дистиллированной воде.

Измерения спектров пропускания полученных образцов проводились на спектрофотометре ПЭ-5400 УФ (190-1000 нм). Исследование морфологии образцов проводилось на атомно-силовом микроскопе NT-MDT NTEGRA Therma.

Для синтеза тонких пленок оксида меди использовалось взаимодействие аммиачного комплекса меди и перекиси водорода. Для синтеза пленок применялись четыре раствора: 1-й - раствор аммиачного комплекса меди $\left[\mathrm{Cu}\left(\mathrm{NH}_{3}\right)_{4}\right]^{2+}$, полученный путем смешивания водных растворов хлорида меди, дистиллированной воды и аммиака:

$$
\begin{aligned}
& \text { 1) } \mathrm{CuCl}_{2} \leftrightarrows \mathrm{Cu}^{2+}+2 \mathrm{Cl}^{-} \\
& \text {2) } \mathrm{Cu}^{2+}+4 \mathrm{NH}_{3} \rightarrow\left[\mathrm{Cu}\left(\mathrm{NH}_{3}\right)_{4}\right]^{2+}
\end{aligned}
$$

2-й и 4-й - дистиллированная вода, 3-й - водный раствор перекиси водорода $\mathrm{H}_{2} \mathrm{O}_{2}$. Дистиллированная вода в промежуточных сосудах необходима как для удаления не адсорбировавшихся на подложку молекул комплекса, так и для того, чтобы снизить загрязнение растворов комплекса и перекиси водорода друг другом.

В ходе последовательного переноса подложки при погружении ее в 1-й раствор на поверхности подложки происходит адсорбция молекул комплекса, при погружении во 2-й раствор избыток комплекса удаляется с поверхности дистиллированной водой, при погружении в 3-й раствор происходит разложение адсорбированного комплекса на поверхности подложки пероксидом водорода, при погружении в 4-й раствор происходит удаление избытка перекиси водорода.

Пленка начинала окрашиваться в однородный желтый цвет на первом цикле, цвет далее сохранялся и становился более ярким. Процедура повторялась заданное количество раз. Для выявления зависимости количества циклов нанесения от толщины пленки процедура синтеза повторялась для проведения 2, 5, 10, 15 циклов наслаивания. Описанный эксперимент был проведен для обоих типов подложек.

Для измерения содержания на поверхности пленок бренстедовских кислотных центров адсорбции с 

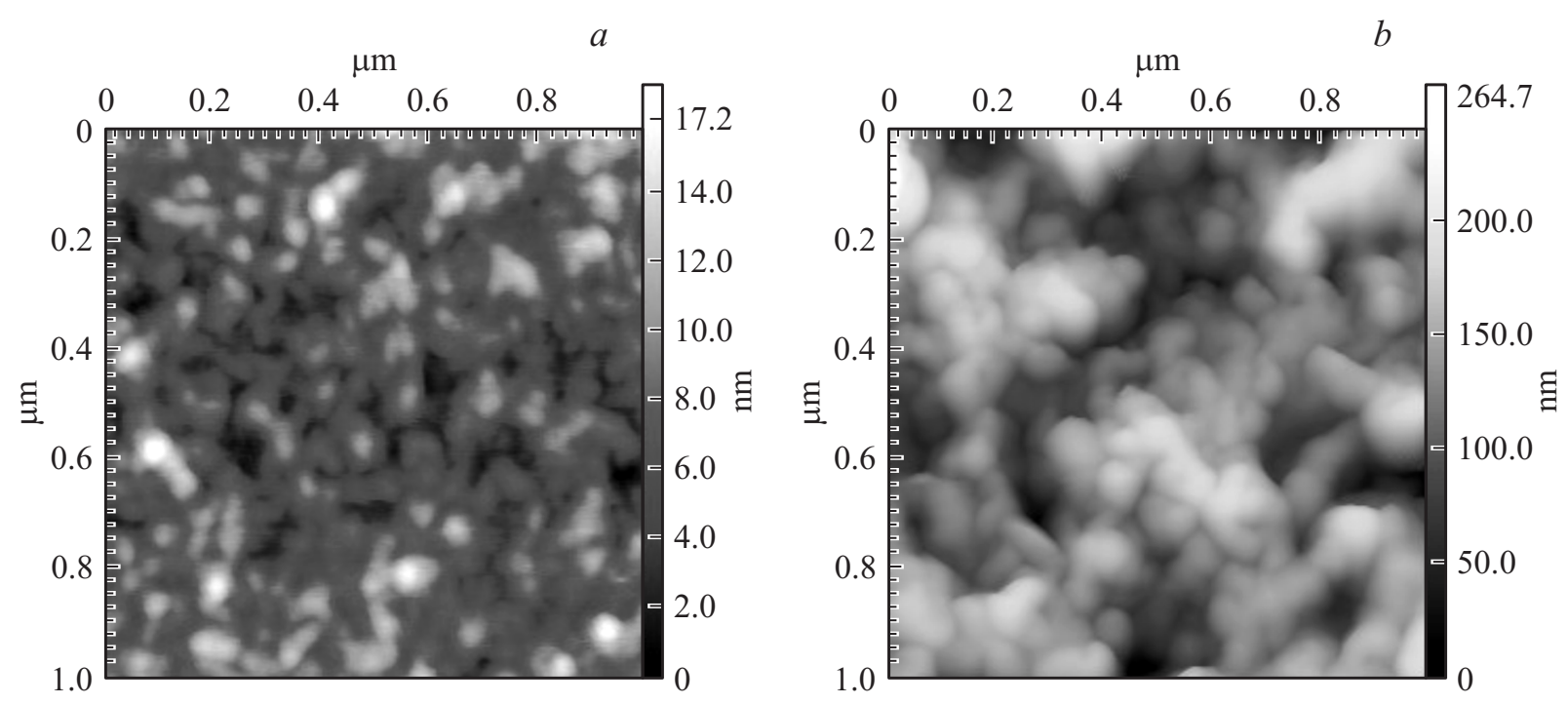

Рис. 1. АСМ-изображение топологии пленки $\mathrm{CuO}_{x}$ размер скана $1 \times 1$ мкм: $a-$ на стеклянной подложке, $b-$ на полиэстерной подложке.

$p K_{a} \approx 2.5$ (ОН-групп кислотного характера) был применен химический индикаторный метод, описанный ранее $[7,18]$. Для центров адсорбции с $p K_{a} \approx 2.5$ индикатором является м-нитроанилин [6]. Содержание поверхностных активных центров с данным значением $p K_{a}$ определяется из фотометрических данных по выражению:

$$
q\left(p K_{a}\right)=\left|\frac{\left|D_{0}-D_{1}\right|}{m_{1}} \pm \frac{\left|D_{0}-D_{2}\right|}{m_{2}}\right| \cdot C_{\text {ind }} \cdot V_{\text {ind }} / D_{0},
$$

где $D_{0}-$ оптическая плотность холостой пробы, полученная при добавлении дистиллированной воды к индикатору, взятому в объеме $V_{\text {ind }}$ и концентрации $C_{\text {ind }} ; D_{1}$ - оптическая плотность раствора индикатора с образцом после установления адсорбционнодесорбционного равновесия; $D_{2}-$ оптическая плотность декантированной воды, в которой образец выдерживался в течение часа, с добавлением индикатора; $m_{1}$ и $m_{2}$ - массы исследуемого образца (в нашем случае определялась поверхностная концентрация относительно площади подложки), соответственно для измерений оптических плотностей $D_{1}$ и $D_{2}$.

\section{3. Экспериментальные результаты}

Тонкие пленки оксидов меди, полученные по реакции разложения аммиачного комплекса перекисью водорода, имели плотную, однородную структуру и обладали адгезией как к стеклянным, так и полиэстерным подложкам. При длительном ультразвуком воздействии не происходило отслаивания пленок.

Атомно-силовая микроскопия морфологии синтезированной пленки $\mathrm{CuO}_{x}$ после проведения 15 циклов наслаивания представлена на рис. 1. Пленки на обоих типах подложек имеют ожидаемую зернистую структуру. На

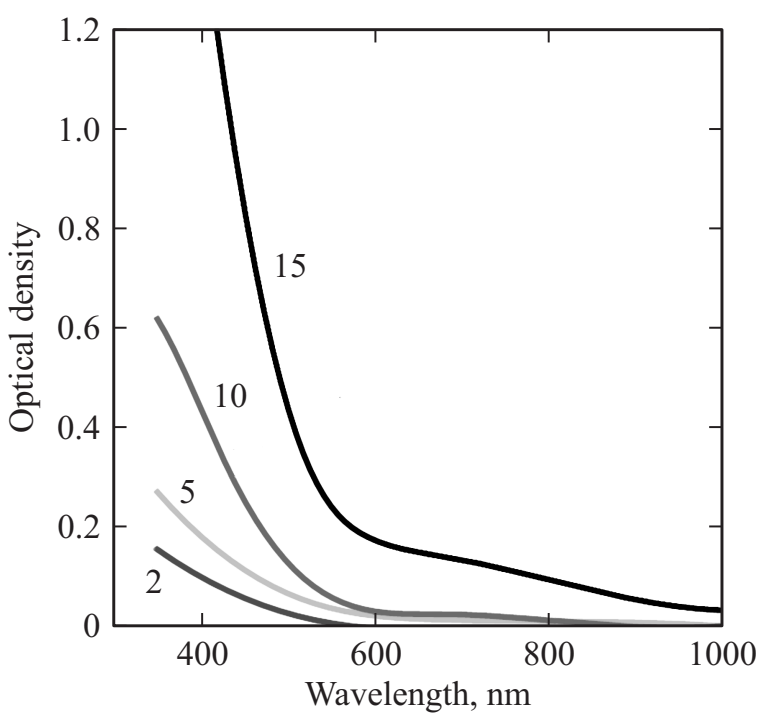

Рис. 2. Зависимости оптической плотности пленок $\mathrm{CuO}_{x}$, полученных в процессе ионного наслаивания после проведения 2 , 5,10 и 15 циклов.

снимке $1 \times 1$ мкм (рис. $1, a)$ можно видеть, что перепад высот не превышает 20 нм для стеклянной подложки и 260 нм для подложки из полиэстера (рис. 1, $b$ ). Так как исходная шероховатость подложек имела близкие значения, можно предположить разный характер роста пленок, приводящий к существенному различию в шероховатости поверхности образца. В первую очередь подобное осаждение зависит от количества центров адсорбции на поверхности подложки. В случае стекла можно ожидать более высокую концентрацию ОН-групп после предварительной обработки в щелочи и соответственно менее рыхлую структуру получаемого слоя. 


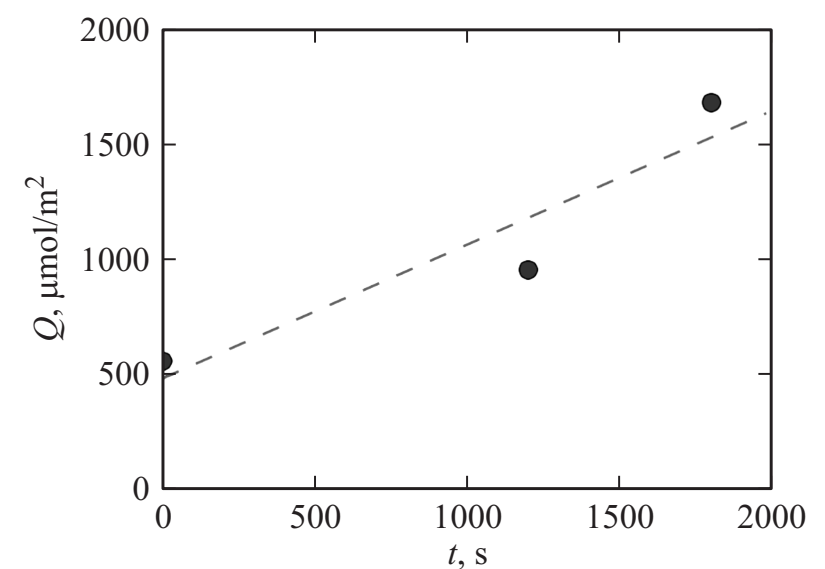

Рис. 3. Зависимость поверхностной концентрации центров адсорбции с $p K_{a} \approx 2.5$ от времени термообработки.

Результаты оптической спектроскопии для пленок на стеклянных подложках показаны на рис. 2. При увеличении количества нанесенного материала растет оптическая плотность пленки. При этом не происходит изменения формы кривой при различном количестве циклов наслаивания, следовательно, процесс наслаивания на первых этапах осаждения слоев и далее имеет одинаковую природу. Аналогичным образом выглядят зависимости для слоев, полученных на полимерной подложке.

Оптическая ширина запрещенной зоны, определенная в координатах Тауца, составила 2.1 эВ, что соответствует справочным значениям ширины запрещенной зоны оксида меди (I) $\mathrm{Cu}_{2} \mathrm{O}$ [1]. На всех спектрах оптической плотности можно видеть точку перегиба, разделяющую спектр на коротковолновую и длинноволновую области. Значение, получаемое интерполяцией коротковолновой части спектра до пересечения с осью энергий, соответствует указанному энергетическому зазору. Можно предположить смешанную природу получаемого оксида, на что указывает длинноволновая составляющая спектра, соответствующая оксиду меди (I) $\mathrm{CuO}$, являющемуся более узкозонным материалом. Форма спектров была идентичной для обоих типов подложек.

При сравнении спектров оптической плотности можно также сделать вывод об ускорении осаждения пленок по мере увеличения количества циклов наслаивания (рис. 2). Это может быть связано как с необходимостью образования некоторого „затравочного“ слоя для роста слоя оксида меди, так и с тем, что высвобождающаяся при протекании реакции медь является катализатором разложения перекиси водорода.

Развитый характер поверхности и смешанный тип оксида указывают на возможность наличия на поверхности большого количества центров адсорбции, интересных для газочувствительных структур. Поэтому было проведено измерение содержания бренстедовских кислотных центров с $p K_{a} \approx 2.5-\mathrm{OH}$-групп кислотного характера, количество которых, согласно результатам ранее проведенных исследований [18], может коррелировать с газочувствительностью оксидных сенсоров на поверхности образцов оксида меди на подложке из стекла в зависимости от времени термообработки при температуре $80^{\circ} \mathrm{C}$. Полученные данные (рис. 3) показывают, что с увеличением времени термообработки содержание рассматриваемых поверхностных центров увеличивается, и в случае обработки в течение 30 мин примерно в 3 раза возрастает по сравнению с исходной концентрацией, составляющей 560 мкмоль/м ${ }^{2}$. Наблюдаемая зависимость может объясняться разложением поверхностных перекисных соединений и активацией хемосорбции молекул физически сорбированной воды с образованием дополнительных гидроксильных групп на поверхности пленки.

\section{Заключение}

Предложенная методика послойного окисления молекул аммиачного комплекса меди перекисью водорода показала возможность получения сплошных однородных слоев оксида меди с адгезией как к стеклянным, так и к гибким полимерным подложкам. Методика позволяет применять автоматизированные установки, использующиеся для ионного наслаивания из растворов (метод SILAR).

Исследование полученных слоев методами атомносиловой микроскопии показало их однородную зернистую структуру. Спектры оптической плотности образцов указывают на смешанный тип оксида меди с преобладанием оксида меди (I) $\mathrm{Cu}_{2} \mathrm{O}$ с шириной запрещенной зоны 2.1 эВ. Поверхностная концентрация центров бренстедовских кислотных центров с $p K_{a} \approx 2.5$ (ОН-групп кислотного характера), определенная химическим индикаторным методом, составляет для исходных пленок 560 мкмоль $/ \mathrm{M}^{2}$ и возрастает в 3 раза при термическом воздействии $80^{\circ} \mathrm{C}$ в течение 30 мин.

Полученные результаты представляют интерес в использовании описанной технологии для создания активных слоев оксида меди в газочувствительных сенсорах, работающих при комнатной температуре.

Работа поддержана грантом государственного задания Министерства образования и науки РФ № 16.2112.2014/К, проектная часть.

\section{Список литературы}

[1] V. Dhanasekaran. Thin Sol. Films, 520 (21), 6608 (2012).

[2] Т.А. Моисеева. Инженерный вестн. Дона, 23 (4), (2012).

[3] S.T. Shishiyanu, T.S. Shishiyanu, O.I. Lupan. Sensors Actuators B: Chemical, 113 (1), 468 (2006).

[4] J. Chen. J. Phys. Chem. C, 112 (41), 16017 (2008).

[5] Chowdhuri. J. Appl. Phys., 92 (4), 2172 (2004).

[6] К. Танабе. Твердые кислоты и основания (М, Мир, 1973).

[7] С.С. Карпова, В.А. Мошников, С.В. Мякин, Е.С. Коловангина. ФТП, 47 (3), 369 (2013). 
[8] H.M. Pathan, C.D. Lokhande. Bulletin Mater. Sci., 27 (2), 85 (2004).

[9] M. Ristov. Thin Sol. Films, 149 (1), 65 (1987).

[10] M. Nair. Appl. Surf. Sci., 150 (1), 143 (1999).

[11] I. Truijen, M.K. Van Bael, H. Van den Rul, J. D’Haen, J. Mullens. J. of Sol-Gel Science and Technology, 41 (1), 43 (2007).

[12] P. Chand, A. Gaur, A. Kumar. Superlattices and Microstr., 60, 129 (2013).

[13] Z. Yang. J. Sol. St. Chem., 180 (4), 1390 (2007).

[14] Y. Gulen. Ceramics Intern., 39 (6), 6475 (2013).

[15] Ю.В. Ваганова, В.Р. Миролюбов, С.В. Катышев, А.В. Ищенко, Е.О. Клюкина. Современные проблемы науки и образования, 3, 817 (2014).

[16] Л.Б. Матюшкин, Д.В. Хондрюков, А.О. Александрова. Патент 156478 RUS (2015).

[17] A.O. Andronov, L.B. Matyushkin, D.V. Hondryukov. Proc. IEEE NW Russia Young Researchers in Electrical and Electronic Engineering Conference (Saint-Petersburg, Russia, 2016), p. 19.

[18] С.С. Карпова, В.А. Мошников, А.И. Максимов, С.В. Мякин, Н.Е. Казанцева. ФТП, 47 (8), 1022 (2013).

Редактор Г.А. Оганесян

\section{The morphology, adsorption and optical properties of copper oxide layers deposited from complex compound solutions}

L.B. Matyushkin ${ }^{1}$, A.A. Reshetnikova ${ }^{1}$, A.O. Andronov' ${ }^{1}$, P.K. Afonicheva ${ }^{1}$, S.V. Myakin ${ }^{2}$, N.V. Permiakov ${ }^{1}$, V.A. Moshnikov ${ }^{1}$

${ }^{1}$ St. Petersburg Electrotechnical University „LETI“, 197376 St. Petersburg, Russia

${ }^{2}$ St. Petersburg State Technological Institute

(Technical university),

190013 St. Petersburg, Russia

Abstract The layer-by-layer deposition technique of gas sensor copper oxide films is described for glass and plastic substrates. The deposition is based on oxidation of copper ammonia complex by hydrogen peroxide. The resulting layers were studied by atomic force microscopy and transmission spectroscopy $(300-1000 \mathrm{~nm})$. The shape of spectra indicates predominance of copper oxide (I) $\mathrm{Cu}_{2} \mathrm{O}$ with corresponding bandgap of $2.1 \mathrm{eV}$. The layers have a continuous granular structure. The surface concentration of Bronsted acid sites having a $p K_{a} \approx 2.5$ ( $\mathrm{OH}$ acidic groups) as determined by an indicator technique is $560 \mathrm{umol} / \mathrm{m}^{2}$ and increased threefold by thermal exposure at $80^{\circ} \mathrm{C}$ for $30 \mathrm{~min}$. These results are of interest to use the described technology for copper oxide active layers in the gas-sensitive sensors operating at room temperature. 